\title{
Spectral and Solvation Properties of Some Dipyrromethene Hydrobromides and Their Oxa- and Thia- Analoges
}

Michail B. Berezin ${ }^{1}$, Olga M. Chernova ${ }^{2}$, Pavel A. Shatunov ${ }^{2}$, Natalia A. Pashanova ${ }^{1}$, Dmitri B. Berezin $^{2}$ and Aleksandr S. Semeikin ${ }^{2}$

${ }^{1}$ Solution Chemistry Institute of Russian Academy of Sciences, Akademicheskaya St., Ivanovo153045, Russian Federation

E-mail:ngm@ihnr.polytech.ivanovo.su

${ }^{2}$ Ivanovo State University of Chemistry and Technology, 7, Engels Av., Ivanovo-153460, Russian Federation

Received: 17 March 2000 / Accepted: 2 April 2000 / Published: 12 June 2000

\begin{abstract}
The spectral and solvatation properties of hydrobromides of $3,3^{\prime}, 4,4^{\prime}, 5,5^{\prime}$ -

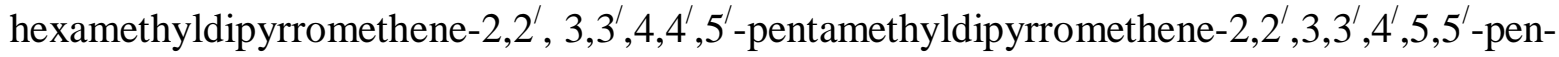
tamethyldipyrromethene-2,2', 1',3,4,5-tetramethyldipyrromethene-2,2', 3,4,5-trimethyldipyrromethene- $2,2^{\prime}$ and their oxa- and thia- analoges in benzene, n-propanol, chloroform, pyridine and N,N-dimethylformamide have been studied. The changes of relative solvation enthalpies are calculated and discussed.
\end{abstract}

Keywords: dipyrromethene, solvation, spectral properties.

\section{Introduction}

Taking into account the important role of porphyrins (chlorophyll, haemin, vitamin $\mathrm{B}_{12}$ and others) in photosynthesis and the development of life on Earth, and also that all of the processes in which the porphyrins take part occur in the liquid phase, it is necessary to investigate solvation properties, not only of porphyrins themselves, but also of the more simple fragments of which they are consist, in particular the dipyrromethenes.

(C) 2000 by MDPI (http://www.mdpi.org). Reproduction is permitted for noncommercial purposes. 
Presently data concerning the influence of their molecular structure on the physicochemical properties of dipyrromethenes is not abundant [1-4]. However this knowledge can be useful, for example, for the development of new syntheses of the porphyrin structure and the determination of porphyrin metabolism mechanisms in living organisms.

The subject of our investigations, compounds 1-7, are complex conjugated systems, which consist of two pyrrole nuclei with methyl group substituents at different positions on the parent molecule (compounds 1-5), and oxa- and thia- analoges of compound 5 possessing one pyrrole fragment and one furan or thiophene nucleus (compounds 6-7).

These compounds differ in the location of their substituents and heteroatoms and, therefore, in their centres of universal and specific solvation. NH-groups are supposed to be solvated by electron donating (proton withdrawing) solvents. Tertiary nitrogen atoms $(-\mathrm{N}=)$ can provide interactions of dipyrromethene molecules with proton donating solvents. The presence of the conjugated $\pi$-system might create conditions for solvation by aromatic solvent molecules. In this respect the following solvents were chosen as examples: benzene as an inert aprotic solvent, dimethylformamide and pyridine as the electron donating ones and propanol and chloroform as the proton donating ones.<smiles>CC1=C(C)C(=Cc2[nH]c(C)c(C)c2C=C2[NH2+]C(C)=C(C)C2=[NH2+])[NH2+]C1</smiles>

(1)<smiles>CC1=C(C)C(=Cc2[nH]cc(C)c2C)C(Br)=[NH+]1</smiles>

(2)<smiles>CC1=[NH+]/C(=C\c2[nH]c(C)cc2C)C(C)=C1C</smiles>

(3)<smiles>CC1=[NH+]/C(=C\c2cccn2C)C(C)=C1C</smiles>

(4)<smiles>CC1=[NH+]C(=Cc2ccco2)C(C)=C1C</smiles>

(6)<smiles>CC1=[NH+]/C(=C\c2ccc[nH]2)C(C)=C1C</smiles>

(5)<smiles>CC1=[NH+]C(=Cc2cccs2)C(C)=C1C</smiles>

(7)

Figure 1. 


\section{Results and Discussion}

The dipyrromethene molecule is a complex chromophore system, a fact that is confirmed by the presence of specific absorption bands in the visible region of the electronic spectrum (Table 1) typical of the solutions of such compounds in organic solvents. In dipyrromethene hydrobromides the proton delocalized on the aza-groups of the pyrrole rings plays the role of an auxochrome, polarizing the chromophore molecule [7]. Changing of number and positions of substituents in the molecule and also changing of nature of the heteroatoms in one of the nuclei has a substantial influence on their electronic absorption spectra and other physicochemical properties.

Table 1. Position $\left(\lambda_{1}, \mathrm{~nm}\right)$ and intensities $\left(\varepsilon \cdot 10^{-3}\right)$ of dipyrromethene hydrobromide absorption bands in methylene chloride.

\begin{tabular}{|c|c|c|c|c|c|c|c|}
\hline Compound & $\mathbf{1}$ & $\mathbf{2}$ & $\mathbf{3}$ & $\mathbf{4}$ & $\mathbf{5}$ & $\mathbf{6}$ & $\mathbf{7}$ \\
\hline$\lambda_{1}$ & 486 & 480 & 478 & 479 & 465 & 425 & 429 \\
$\varepsilon \cdot 10^{-3}$ & 98.6 & 76.0 & 95.8 & 37.9 & 76.0 & 28.6 & 29.1 \\
\hline
\end{tabular}

Hexamethyl substituted dipyrromethene $\mathbf{1}$ itself has a symmetrical structure in which the excess positive charge of the $\mathrm{H}$ atom from the $\mathrm{HBr}$ moiety is delocalized on both pyrrole rings. The StuartBrigleb models have shown that any changes in the molecular structure can induce conformational rearrangements and changes in polarization. It is apparent from the data in Table 1 that a decrease in the number of methyl groups in the molecules $\mathbf{1 - 5}$ causes the hypsochromic (up to $20 \mathrm{~nm}$ ) shift of the absorption band in the electronic spectra and changes in its intensity (the data are given for methylene chloride solutions). Removing just one substituent (compounds 2, 3) hypsochromically shifts the absorption band by 6- $8 \mathrm{~nm}$ compared to compound $\mathbf{1}$. The change is due to a less perfect (incomplete) high polarization in comparison to the arenes of the pyrrolic $\pi$-system [8]. For this reason even changes in the positions of the substituents while their number remains constant has a considerable influence on chromophore properties. Thus the presence of free (unsubstituted) $\alpha$ or $\beta$ positions in one of the pyrrole rings (compounds $\mathbf{2 - 3}$ ) has a slight influence on the position of the band but changes its intensity strongly. This is proof of the nonequivalence of the $\alpha$ and $\beta$ positions of the pyrrole nuclei, included in the general conjugated dipyrromethene system, due to the unequal electronic action of the bridging $-\mathrm{CH}=$ methylene group.

$\mathrm{N}$-methyl substitution in the dipyrromethene molecule (compound 4) has almost no effect on the energy of the absorbed light quanta, however, it decreases considerably the probability of the absorption. These facts could mean that the delocalization of $\mathrm{H}^{+}$- charge in $\mathrm{N}$-methyl substituted dipyrromethene is maintained.

The substitution of nitrogen heteroatoms in one of the pyrrole nuclei by oxygen (compound 7) shifts 
the absorption band maximum to the border of the visible region by $40 \mathrm{~nm}$ and strongly lowers its intensity. Such considerable changes in the electronic spectra apparently are connected with the fact that the positive charge cannot be delocalized on those atoms, that is, the positive charge of $\mathrm{H}^{+}$and an anion $\mathrm{Br}^{-}$are localized on only one of pyrrole nuclei.

The influence of solvent nature on the electronic spectra of the discussed compounds is also specific. The data of the absorption band positions in the electronic spectra of dipyrromethenes and their derivatives in organic solvents of different nature are shown in Table 2. The first (longwave) absorption band of dipyrromethene hydrobromides (1-4) looks like a band of $n \pi$ transition owing to high intensity and hypsochromic shift with a replacement of the nonpolar solvent (benzene) by the polar one (propanol, etc.). However it usually disappears in the proton donating solvents (DMF, pyridine) where the loss of the $\mathrm{HBr}$ molecule is supposed to be happened.

Table 2. Electronic spectra absorption band positions of dipyrromethenes and their analoges in different solvents $\left(\lambda, \mathrm{nm}, \mathrm{m}_{\text {solution }} \sim 5^{*} 10^{-5} \mathrm{~mol}^{*} \mathrm{~kg}^{-1}\right)$.

\begin{tabular}{|c|c|c|c|c|c|}
\hline \multirow[t]{2}{*}{ Compound } & \multicolumn{5}{|c|}{ Solvent } \\
\hline & PrOH & $\mathrm{CHCl}_{3}$ & DMF & $\mathbf{P y}$ & $\mathrm{C}_{6} \mathrm{H}_{6}$ \\
\hline \multirow{2}{*}{1} & 478 & 473 & 435 & 448 & 484 \\
\hline & 361 & 362 & & & 364 \\
\hline \multirow{2}{*}{2} & 463 & 473 & 415 & 421 & 479 \\
\hline & 371 & 370 & & & 425 \\
\hline \multirow{2}{*}{3} & 468 & 466 & 428 & 434 & 474 \\
\hline & 356 & 354 & & & 361 \\
\hline \multirow{2}{*}{4} & 474 & 476 & 402 & 433 & 485 \\
\hline & 376 & 378 & & & 382 \\
\hline \multirow{2}{*}{5} & 463 & 455 & 390 & 400 & 462 \\
\hline & 401 & 374 & & & \\
\hline \multirow{2}{*}{6} & 408 & 424 & 368 & 380 & \\
\hline & 370 & & & & \\
\hline 7 & 412 & 427 & 350 & 378 & 420 \\
\hline
\end{tabular}

It is possible to consider that changes in exited state solvation play the main role in the changes of the electronic spectrum [7]. The comparison of the first band positions in the nonpolar and polar solvents (Table 2) shows that depending on the dipyrromethene hydrobromide structure, the transition of the molecule in an exited state is accompanied almost always by a decrease of its electronic system dipole. In the proton accepting solvents like pyridine and DMF a dissolution of the dipyrromethene hydrobromide occurs together with removal of $\mathrm{HBr}$ resulting in the an electronic spectrum typical of free dipyrromethenes [2]. The comparison of the data in DMF and pyridine shows that for free base dipyrromethenes a considerable solvatochromic effect takes place in solvents similar in nature. The absorption band of the pyridine solutions of dipyrromethenes and their analoges are shifted batochro- 
mically in comparison with the DMF ones, possibly caused by their being bound up by their solvatation of a $\pi, \pi^{*}$ - type by the $\pi$-deficient pyridine. In general a complex dependence of the band positions in the electronic spectra of the compounds 1-7 on their structures is observed because of the combined action both electronic and steric effects of substituents and the influence of the nature of the heteroatoms.

The changes in molal dissolution enthalpies $\Delta$ sol. $\mathrm{H}^{\mathrm{m}}=\mathrm{f}(\mathrm{m})$ of compounds 1-7 do not depend (within the the measurement error) on the concentration of dissolved pigment in the region of working concentrations used $\left(10^{-5}-10^{-4} \mathrm{~mol}^{*} \mathrm{~kg}^{-1}\right)$. The experimental values of standard enthalpy changes during a dissolution ( $\Delta$ sol. $\mathrm{H}^{0}$ as an average of five $\Delta$ dissol. $\mathrm{H}^{\mathrm{m}}$ measurements) and a transition $\left(\Delta \mathrm{tr} . \mathrm{H}^{\mathrm{m}}\right)$ of the studied compounds from propanol to another organic solvents are given in Table 3. Dipyrrolylmethene hydrobromides are expected to possess crystal lattices of different stability, unequal effective molecular volumes, and to differ in intermolecular interaction energies.

The thermal dissolution effect, as for porphyrin [9], is determined by

$$
\Delta \text { sol. } \mathrm{H}^{0}=\Delta \mathrm{cr} \cdot \mathrm{H}^{0}+\Delta \text { solv } \cdot \mathrm{H}^{0}+\Delta \text { conf. } \mathrm{H}^{0}
$$

where $\Delta \mathrm{cr} \cdot \mathrm{H}^{0}=$ energy of a crystal lattice, $\Delta$ solv. $\mathrm{H}^{0}=$ energy of a solvatation, and $\Delta$ conf. $\mathrm{H}^{0}=$ energy of conformational changes associated with differences in the forms in which the the heterocycle and its substituents exist in the solid state and in solutions. Since the crystal lattice energies of the compounds studied are unknown to date, it would be best to analyze the enthalpy characteristics of dissolution using the enthalpy of a transition from a slightly solvating solvent to the one under investigation in each case.

The experimental data show a strong dependence of changes in substance-solvent enthalpy for a given structure, up to the insolubility of some of the compounds in benzene. In connection with this the transition enthalpies are calculated not from benzene, usually taken as a standard solvent, but from propanol. In this case propanol appeared to be the least solvating with respect to the majority of the compounds studied since the dissolution enthalpies for it are the most positive. Probably this is strongly related with the structure of propanol and some energetic expenditures required to create cavities in the structure of the solvent. Apparently these energetic losses are so large that cannot be covered by the enthalpy component of a solvatation process of the polarized dipyrromethene hydrobromide molecules and their analoges by the polar propanol. Within the dipyrromethene series (compounds 1-5), hexamethyl substituted dipyrromethene 1 obviously possesses the most effective molecular volume, and compound $\mathbf{5}$, which has no substituents on one of the pyrrole rings possesses the least volume. Thus endothermicity of the dissolution of dipyrromethenes in propanol decreases in the order: $\mathbf{1}>\mathbf{2}>\mathbf{4}>\mathbf{5}$.

As it turned out, during our experiments it was observed that even negligible structural perturbations in the chromophore molecules sharply changed their solvation characteristics. For example, in comparison with hexamethyl substituted dipyrromethene $\mathbf{1}$, the $3,3^{\prime}, 4,4^{\prime}, 5^{\prime}$ - pentamethyldipyrrometh- 
ene (2) is almost insoluble in propanol and benzene, while its $\beta$ - unsubstituted derivative (compound 3) is much more soluble in both solvents.

Table 3. Standard changes of dissolution enthalpies $\left(\Delta\right.$ sol. $\left.H^{0}\right)$ and transition enthalpies $\left(\Delta \operatorname{tr} . H^{0}\right)$ of dipyrromethene hydrobromides and their analoges $\left(\mathrm{kJ}^{*} \mathrm{~mol}^{-1}\right)$.

\begin{tabular}{|c|c|c|c|c|c|c|c|c|c|}
\hline \multirow{2}{*}{ Compound } & \multirow{2}{*}{$\begin{array}{c}\mathrm{PrOH} \\
\Delta \mathrm{solH}^{0}\end{array}$} & \multicolumn{2}{|c|}{$\mathrm{CHCl}_{3}$} & \multicolumn{2}{|c|}{ DMF } & \multicolumn{2}{|c|}{ Pyridine } & \multicolumn{2}{|c|}{$\mathrm{C}_{6} \mathrm{H}_{6}$} \\
\hline & & $\Delta \mathrm{solH}^{0}$ & $\Delta \operatorname{tr} H^{0}$ & $\Delta \mathrm{solH}^{0}$ & $\Delta \operatorname{tr} H^{0}$ & $\Delta$ solH $^{0}$ & $\Delta \operatorname{tr} H^{0}$ & $\Delta$ solH $^{0}$ & $\Delta \operatorname{trH}^{0}$ \\
\hline 1 & $\begin{array}{l}35.1 \\
\pm 1.1\end{array}$ & $\begin{array}{c}4.8 \\
\pm 0.3\end{array}$ & -30.3 & $\begin{array}{r}18.5 \\
\pm 0.5\end{array}$ & -16.6 & & & $\begin{array}{l}20.5 \\
\pm 0.7\end{array}$ & -14.6 \\
\hline 2 & & $\begin{array}{c}4.7 \\
\pm 0.7\end{array}$ & & $\begin{array}{c}9.2 \\
\pm 1.0\end{array}$ & & $\begin{array}{l}13.5 \\
\pm 1.4\end{array}$ & & & \\
\hline 3 & $\begin{array}{r}23.3 \\
\pm 1.5 \\
\end{array}$ & $\begin{array}{r}10.0 \\
\pm 1.2 \\
\end{array}$ & -13.3 & $\begin{array}{c}3.5 \\
\pm 0.3\end{array}$ & -19.8 & $\begin{array}{r}18.9 \\
\pm 1.3 \\
\end{array}$ & -4.4 & $\begin{array}{r}30.3 \\
\pm 3.0 \\
\end{array}$ & 7.0 \\
\hline 4 & $\begin{array}{r}21.7 \\
\pm 2.0\end{array}$ & $\begin{array}{c}0 \\
+1.5 \\
\end{array}$ & -21.7 & $\begin{array}{c}7.1 \\
\pm 0.5\end{array}$ & -14.6 & $\begin{array}{l}-16.7 \\
\pm 1.2\end{array}$ & -38.4 & & \\
\hline 5 & $\begin{array}{r}16.9 \\
\pm 1.1\end{array}$ & $\begin{array}{c}8.3 \\
\pm 0.8\end{array}$ & -8.6 & $\begin{array}{c}5.3 \\
\pm 0.5\end{array}$ & -11.6 & $\begin{array}{l}18.7 \\
\pm 0.5\end{array}$ & 1.8 & & \\
\hline 6 & $\begin{array}{l}32.1 \\
\pm 1.5\end{array}$ & $\begin{array}{r}14.5 \\
\pm 1.2\end{array}$ & -17.6 & $\begin{array}{c}7.8 \\
\pm 0.7\end{array}$ & -24.3 & $\begin{array}{l}-19.7 \\
\pm 1.6\end{array}$ & -51.8 & & \\
\hline 7 & $\begin{array}{l}22.1 \\
\pm 0.5\end{array}$ & $\begin{array}{c}1.9 \\
\pm 0.2\end{array}$ & -20.2 & $\begin{array}{l}-40.3 \\
\pm 1.5\end{array}$ & -62.4 & $\begin{array}{c}-17.6 \\
\pm 0.5\end{array}$ & -39.7 & & \\
\hline
\end{tabular}

Chloroform as a proton donating solvent could solvate dipyrromethene hydrobromide molecules by means of the formation of $\mathrm{Br}^{-}$... $\mathrm{HCCl}_{3}$ hydrogen bonds. For this high bromide ion and proton delocalizations on the pyrrole nuclei are necessary. On the base of the enthalpies of a dipyrromethene transition to chloroform (Table 3) and the assumption made one can suppose that a proton is most delocalized in the symmetrically substituted compound $\mathbf{1}$ and least in compound $\mathbf{5}$, whicht is in agreement with the data from the electronic absorption spectra. Thus one can think that the degree of the proton delocalization on the pyrrole nuclei of the dipyrromethene molecules decreases in the series: $\mathbf{1}>\mathbf{4}>\mathbf{3}>\mathbf{5}$.

As was mentioned above, the interaction of dipyrromethene hydrobromides with proton accepting solvents is apparently accompanied by a removal of $\mathrm{HBr}$ and also by $\pi-\pi$ - interactions in the case of pyridine. The high values of the enthalpies of the $\mathrm{N}$ - methyl substituted dipyrromethene (4) transition to pyridine is conditioned by the dominating influence of the methyl group directly bound up with the nitrogen atom and the increase of the (4) - pyridine $\pi$ - $\pi$ type interactions.

As follows from the data of Table 3, some of the studied compounds are not soluble in benzene. One of the possible reasons for this fact may be in a localization of the positive charge in one of the pyrrole nuclei and a formation of a salt with $\mathrm{Br}^{-}$(for example, ammonium halides are insoluble in benzene). 


\section{Experimental}

The dipyrromethenes were synthesized by condensation of 2- formyl substituted five-member heterocycles (furan, thiophene, substituted pyrroles) with 2,3,4- trimethylpyrrole in methanol in the presence of $\mathrm{HBr}$ [2]. This results in the formation of dipyrromethenes and their analoges as the corresponding hydrobromides. Before the experiments the compounds were additionally recrystallized from a mixture of methylene chloride and methanol and dried to a constant mass under vacuum at $350^{\circ} \mathrm{K}$. All solvents were purified using standard methods [5]. The water content was measured by Karl Fischer titration and did not exceed $0.02 \%$. The thermochemical measurements were conducted in a precise calorimeter equipped with a variable temperature isothermal cover [6]. The relative error of the measurements was $\pm 5 \%$. The electronic absorption spectra were recorded on a Specord M40 spectrophotometer under similar conditions for all the compounds $\left(298.15^{\circ} \mathrm{K}\right.$, molal solution concentrations were $\sim 5^{*} 10^{-5} \mathrm{~mol}^{*} \mathrm{~kg}^{-1}$ ).

\section{References and Notes}

1. Falk, H. The Chemistry of Linear Oligopyrroles and Bile Pigments; Springer: Wien - New York, 1989; p 621.

2. Berezin, M.B.; Semeykin, A.S.; Antina, E.V.; Pashanova, N.A.; Lebedeva, N.Sh.; Bukushina, G.B. Rus. J. General Chemistry 1999, 69, 2040-2047.

3. Lebedeva, N.Sh.; Antina, E.V.; Berezin, M.B.; Semeykin, A.S.; Bukushina, G.B. Rus. J. Physical Chemistry 2000, 75, 1141-1146.

4. Pashanova, N.A.; Semeykin, A.S.; Berezin, M.B. Rus. J. General Chemistry 1999, 69, 1537-1541.

5. Gordon, A.; Ford, R. Sputnik khimika; Mir: Moscow, 1976; p 542.

6. Abrossimov, V.X.; Korolev, V.V. Solution Calorimetry. Experimentalnie methodi khimii rastvorov; Nauka: Moscow, 1995; pp 239-284.

7. Terenin, A.N. Photonics of Dye Molecules and Related Organic Compounds; Nauka: Leningrad, 1967; p 616.

8. Berezin, B.D.; Berezin, D.B. Modern Course in Organic Chemistry; Vysshaya Shkola: Moscow, 1999; p 768.

9. Berezin, M.B.; Krestov, Al. G. Rus. J. Physical Chemistry 1996, 70, 473-477.

Samples Availability: Available from the authors.

(C) 2000 by MDPI (http://www.mdpi.org). Reproduction is permitted for noncommercial purposes. 